\title{
A REVISTA ÍNTIMA EM MULHERES COMO CONDIÇÃO PARA O INGRESSO EM UNIDADES PRISIONAIS: ANÁLISE À LUZ DA JURISPRUDÊNCIA DA CORTE INTERAMERICANA DE DIREITOS HUMANOS
}

\author{
João Matheus Amaro de Sousa ${ }^{1}$ \\ Italo Farias Braga ${ }^{2}$ \\ Arthur Leite Lomônaco ${ }^{3}$
}

\begin{abstract}
Resumo: A revista íntima é adotada em alguns estabelecimentos prisionais brasileiros como condição para ingresso do público feminino. Tal medida, quando não realizada de modo excepcional, viola direitos fundamentais constitucionais, a exemplo do princípio fundamental da dignidade da pessoa humana. Assim, a finalidade da pesquisa é realizar uma análise da medida, à luz da jurisprudência da Corte Interamericana de Direitos Humanos (CORTEIDH). Ergue-se como hipótese a possiblidade de que o controle de convencionalidade é instrumento apto a afastar essas práticas, haja vista a existência de outros procedimentos mais eficazes e menos invasivos, como os escâneres corporais.
\end{abstract}

Palavras-chave: Controle de Convencionalidade. CORTEIDH. Revista Íntima. Unidade Prisional. Direitos humanos.

\section{THE INTIMATE JOURNAL IN WOMEN AS A CONDITION FOR ENTERING PRISON UNITS: ANALYSIS IN THE LIGHT OF THE JURISPRUDENCE OF THE INTER-AMERICAN COURT OF HUMAN RIGHTS}

\begin{abstract}
The intimate magazine is adopted in some Brazilian prisons as a condition for the entrance of the female public. Such a measure, when not carried out exceptionally, violates fundamental constitutional rights, such as the fundamental principle of human dignity. Thus, the purpose of the research is to carry out an analysis of the measure, in the light of the jurisprudence of the Inter-American Court of Human Rights (CORTEIDH). As a hypothesis, the possibility arises that the control of conventionality is an instrument capable of removing these practices, given the existence of other more effective and less invasive procedures, such as body scanners.
\end{abstract}

Keywords: Conventionality Control. CourtIDH. Intimate Magazine. Prison Unit. human rights.

\footnotetext{
${ }^{1}$ Mestrando em Direito Constitucional Público e Teoria Política pelo Programa de Pós-graduação em Direito da Universidade de Fortaleza (PPGD-UNIFOR). Bolsista Yolanda Queiroz. E-mail: matheusamaro15@gmail.com. Currículo Lattes: http://lattes.cnpq.br/7530486832086965. ORCID: http://orcid.org/0000-0002-7270-8361.

${ }^{2}$ Doutorando em direito constitucional pela universidade de Fortaleza, mestre em direito constitucional pela universidade de fortaleza. Bolsista funcap:E-mail: italofbraga@gmail.com, Currículo Lattes: http://lattes.cnpq.br/0001364627398599, ORCID: http://orcid.org/0000-0002-7351-8498

${ }^{3}$ Mestrando em Direito Constitucional Público e Teoria Política pelo Programa de Pós-graduação em Direito da Universidade de Fortaleza (PPGD-UNIFOR). E-mail: arthurlomonaco@hotmail.com. Currículo Lattes: http://lattes.cnpq.br/2873094172055601. ORCID: http://orcid.org/0000-0002-4312-7226.
} 


\section{Introdução}

Em 05 de junho de 2013, o Tribunal de Justiça do Estado do Rio Grande do Sul proferiu acórdão ${ }^{4}$ no sentido de absolver uma mulher que havia sido presa em flagrante pelo fato de ter sido encontrada droga em seu corpo após realização do procedimento de revista íntima, quando tentava adentrar um presídio de segurança máxima. Aduziram os desembargadores, em suma, que a prova era ilícita para condenação, seja por ser crime impossível, já que todas as mulheres eram obrigatoriamente sujeitas a revista íntima, o que impossibilitaria o cometimento do ilícito, seja por ser o procedimento de revista exageradamente invasivo e violador de direitos da mulher.

Assim, malgrado o caso tenha chegado ao Supremo Tribunal Federal (STF), ${ }^{5}$ sendo inicialmente analisado na sessão de julgamento do dia 28 de outubro de 2020, houve sua suspensão, haja vista o fato de que um dos ministros da Corte se posicionou no sentido contrário ao pugnado pelo então relator, ministro Edson Fachin, aduzindo que a revista íntima é medida unicamente excepcional, de modo que houve o pedido de vistas dos autos.

Deste modo, há controvérsia evidente e importância quanto à possibilidade e os reflexos das revistas íntimas no ordenamento jurídico brasileiro. Isso porque, de um lado, se tem a proteção dos direitos das mulheres, em especial ante a nova "onda" de proteção de direitos humanos que permeia o ordenamento, e, de outra parte, tem-se uma necessidade de proteção e tutela da sociedade, que se reflete em uma tutela coletiva, a qual não há de ser olvidada das análises jurídicas.

Ergue-se como hipótese principal a necessidade de o Estado brasileiro, nos termos do controle de convencionalidade, honrar o compromisso firmado com as normas e decisões internacionais que dele faça parte. Assim, deve-se perquirir acerca das revistas íntimas em relação ao ordenamento nacional e internacional e, sobretudo, quanto à aceitabilidade deste tipo de norma perante o controle amplo de constitucionalidade auferido sob os pilares do garantismo, teoria constitucional adepta a proteção e tutela dos direitos humanos.

\footnotetext{
4 “APELAÇÃO-CRIME. TRÁFICO ILÍCITO DE ENTORPECENTES. TENTATIVA DE INGRESSO NA CASA PRISIONAL COM DROGAS” (TJ-RS - 3 Câmara - Apelação nº 70053559068 - Relator: Diógenes V. Hassan Ribeiro - Publicação: 18/07/2013).

${ }^{5}$ Brasil (2020a).
} 
Com os objetivos de compreender o que na realidade conforma a revista íntima, que posição assumem os tribunais superiores em relação à matéria e qual o comportamento da Corte Interamericana de Direitos Humanos (CORTEIDH) no que concerne ao assunto, este ensaio tem as seguintes perquisições: - O que se entende pela revista íntima no ordenamento jurídico brasileiro? - Os tribunais superiores autorizam ou não estas práticas? - Qual a posição da CORTEIDH sobre as revistas íntimas nos países signatários de convenções?

Com referência aos aspectos metodológicos, a pesquisa ora sob relato é descritiva, uma vez que se almeja desenvolver e esclarecer a temática, tomando por base normas internacionais, de modo a deixar transparente a correta solução da celeuma ora sob escólio. Ademais, deve-se enaltecer a temática por abordar pontos pertinentes à violação de direito de mulheres, que vem constantemente em busca de retirar qualquer tipo de caráter vulnerável oriundo do seu sexo. Ademais, escrito, também, faz busca jurisprudencial, analisando os precedentes envoltos no caso, com demandas nos sítios eletrônicos do STJ, do STF e da CORTEIDH.

Por fim, este experimento acadêmico é expresso na seguinte divisão: $1^{\mathrm{a}}$ ) O que é a revista íntima: fundamentos constitucionais e também legais; análise garantista; $2^{\mathrm{a}}$ ) a revista íntima da visão do STF e STJ; e $3^{\text {a }}$ ) a revista íntima e a CORTEIDH.

O que se almeja, in hoc sensu, na tarefa universitária sob relação, é evidenciar o fato de que o procedimento de revista íntima não deve ser realizado de maneira a impor como condição para ingresso aos presídios, uma vez serem eles claros violadores de garantias mínimas da mulher, como dignidade da pessoa humana, intimidade, honra e integridade física, moral e psíquica.

\section{Os direitos das mulheres como direitos de grupo em situação de vulnerabilidade}

Antes de adentrar propriamente a compreensão acerca de revistas íntimas, ou limitações investigativas ou mesmo em limites da condição de apenado em execuções penais, faz-se necessário compreender o âmbito de implicação destes direitos. Isto é, tem-se que entender sistemicamente o direito, mas com o aprofundamento no subsistema de direito e defesa das mulheres. 
Em primeira instância, deve-se entender que o direito das mulheres adentra o conceito de direito das minorias. Por direito das minorias, compreende-se em um subgrupo de percepção de direitos que afeta grupos historicamente dominados, ou grupos fora daqueles típicos de dominação. Portanto, direito das minorias é um reforço dos direitos fundamentais, na tutela contramajoritária de proteção à pessoa humana (MARTINS, MITUZANI, 2011).

Aqui cabe salientar que, embora a mulher seja maioria numérica, esta não assume uma posição de dominação socioideológica. Assim, em composição com as ideias desses autores, a mulher constitui um sul epistemológico. (SANTOS; MENESES; NUNES, 2004).

É nesse conceito de um sul epistemológico, isto é, um conceito de pensamento próprio, autóctone, da necessidade de perceber que a mulher tem valor intrínseco como grupo, que se constitui uma evolução histórica na percepção de proteção a direitos (GOELLNER, 2007). Assim, tem-se uma formação própria de direitos, no qual se nota um machismo estrutural, com normas que segregam e ferem as mulheres de maneira institucionalizada e gradualmente se divisa uma formação de um direito próprio de proteção e tutela às mulheres.

Deste contexto, formam-se direitos, como aqueles decorrentes da Lei Maria da Penha, normas de diferenciação ativa e uma percepção de que as normas legais e administrativas devem compreender as mulheres como grupo próprio, com direitos e argumentos jurídicos não restritos à mera legalidade ou simplesmente à isonomia. Quando se fala em direitos de mulheres, tem-se uma formação sócio-histórica que rompe conceitos previamente estabelecidos e culmina numa nova visão de direito (BREGA FILHO; BRITO ALVES, 2009).

Não obstante essa compreensão das mulheres como minoria, elas integram grupo em situação de vulnerabilidade, uma vez que não apresentam caracteres linguísticos, éticos e religiosos em comum. Além disso, estão dispersas no território do Estado, em posição de não dominância (quantitativa e/ou qualitativamente). Isto diferencia de minoria, haja vista que esta é conceituada como a junção de dois elementos, quais sejam: a) objetivos - um grupo numericamente inferior ao restante da população de um Estado, em posição não dominante, cujos membros gozem de características linguísticas, étnicas e religiosas; e b) subjetivo - a vontade de continuar pertencendo ao grupo de modo a preservar a cultura, as tradições, a religião ou o idioma. Ocorre que nem sempre o elemento objetivo numérico é suficiente para 


\section{A REVISTA ÍNTIMA EM MULHERES COMO CONDIÇÃO PARA O INGRESSO EM UNIDADES PRISIONAIS: ANÁLISE À LUZ DA JURISPRUDÊNCIA DA CORTE INTERAMERICANA DE DIREITOS}

HUMANOS

defini-la, já que, na África do Sul, os negros eram maioria a despeito da vivência em regime de apartheid (CAPOTORTI, 1979).

Assim, ausente o elemento objetivo, por inexistir a comunhão de características linguísticas, éticas e religiosas, não restam dúvidas de que os direitos das mulheres se configuram como direito em situação de vulnerabilidade. Caso contrário, presente o referido elemento, trataria de direito das minorias. Cumpre, ainda, expressar que, a despeito da divergência entre a natureza jurídica de um e doutra, os direitos assim classificados merecem igualmente ser respeitados e defendidos pelo Estado, pela sociedade civil, pela Família, entre outras organizações e agrupamentos.

Com efeito, a interpretação das visitas íntimas implica diretamente a compreensão ou re-compreensão do que seria a isonomia perante o grupo vulnerável mulher. Isso porque, de primeiro plano, tem-se a mulher como sujeito que depende de uma isonomia material na qual a regra comum, se mera verificação ou investigação, é insuficiente para garantir a condição própria de dignidade esperada para este grupo.

\section{Fundamentos legais e constitucionais da revista íntima: análise garantista}

Os contatos dos presos com o mundo exterior são restritos, por condição natural a da restrição da liberdade decorrente do cárcere. Assim, a Lei de Execuções Penais (Lei 7.210/84 - LEP) estabelece restrições à comunicação do preso com o mundo exterior, bem como a possibilidade do controle dos itens recebidos por este, com o intuito de garantir os princípios da hierarquia e disciplinas típicos do sistema prisional.

A doutrina traz diversas críticas ao modelo de disciplinamento típico do sistema carcerário, vez que a disciplina, por tantas vezes, suplanta o objetivo de ressocialização (MACHADO; SLONIAK, 2015). Para fins acadêmicos, entretanto, este escrito não busca discutir os objetivos de restringir a comunicação, mas supõe, de saída, que esta existe.

Assim, dentre os procedimentos previstos, existe o objeto de análise da pesquisa, que é a revista íntima, consistindo esta, em suma, na determinação, pelo agente estatal, de que a mulher retire suas vestimentas e seja sujeita à inspeção de suas cavidades corporais. Este procedimento foi considerado degradante pela legislação nacional, de modo que foi elaborada 
a Lei $\mathrm{n}^{\mathrm{o}} .13 .271$ de 15 de abril de 2016, dispondo ela em sua ementa e Art. $1^{\text {o }}{ }^{6}$ que as revistas íntimas devem ocorrer e ser realizadas por profissionais femininas.

Ocorre que o mero fato de existir o procedimento feito por profissionais femininas não o torna menos degradante e humilhante na condição de mulher. Ademais, traz uma consequente criminalização da família, que ultrapassa a pessoa do condenado, se estabelece mais um parâmetro de desigualdade de gênero não aceitável em ordenamentos jurídicos civilizados (AYALA REBOLLEDO, 2019).

Sucede que, no texto inicial da norma, havia artigo que previa expressamente a vedação da revista dentro dos presídios, todavia, quando promulgada a lei, foi revogado o citado artigo. Deste modo, a Lei no ${ }^{\circ} 13.271$ evidenciou a vedação unicamente em sua ementa, não sendo feita qualquer menção nos artigos nele dispostos.

O fato de não haver menção expressa nos seus dispositivos legais de que a vedação deve ser aplicada dentro dos presídios brasileiros, ensejou na manutenção da prática das revistas íntimas. Inclusive alguns estabelecimentos penais evitam a realização generalizada, enquanto outros não, de modo que a falha do legislador ao não disciplinar a de maneira hábil a vedação, facultou, ainda, a possibilidade da medida.

Igualmente, alguns estados - como Amazonas, Bahia, Ceará, Espírito Santo, Maranhão, Mato Grosso, Pernambuco, Paraná, Rio de Janeiro, Rondônia, Rio Grande do Sul, Sergipe, São Paulo e Tocantins - já têm elaborado regulamentos de competência estadual, no qual preveem expressamente a vedação de revista íntima. Para tanto, cita-se o exemplo do Estado do Ceará, que, pela Portaria nº 1714/2014, elaborou o Regimento Geral dos Estabelecimentos Prisionais do Estado do Ceará, disciplinando no seu Art. 146. ${ }^{7}$

\footnotetext{
${ }^{6}$ Dispõe sobre a proibição de revista íntima de funcionárias nos locais de trabalho e trata da revista íntima em ambientes prisionais. Art. $1^{\circ}$ As empresas privadas, os órgãos e entidades da administração pública, direta e indireta, ficam proibidos de adotar qualquer prática de revista íntima de suas funcionárias e de clientes do sexo feminino (BRASIL, 2020b).

7 “Art.146 - Antes e depois das visitas os presos poderão ser submetidos à revista. §1 $1^{\circ}$ - Os visitantes deverão ser revistados antes de adentrarem na unidade. $2^{\circ}$ - A revista será feita por Agente Penitenciário do mesmo sexo, sendo vedados toque vaginal e retal, bem como exames que atentem contra a dignidade do revistado. $\$ 3^{\circ}-\mathrm{O}$ Estado deverá utilizar-se de todos os recursos tecnológicos possíveis, no sentido de minimizar os constrangimentos que as revistas íntimas impõem àqueles que a elas são submetidos. $\S 4^{\circ}$ - A revista em menores realizar-se-á na presença dos pais ou responsáveis, observando-se o disposto nos parágrafos anteriores" (ESTADO DO CEARÁ, 2020).
} 


\section{A REVISTA ÍNTIMA EM MULHERES COMO CONDIÇÃO PARA O INGRESSO EM UNIDADES PRISIONAIS: ANÁLISE À LUZ DA JURISPRUDÊNCIA DA CORTE INTERAMERICANA DE DIREITOS}

HUMANOS

Verifica-se, então, que alguns estados acompanham o entendimento de que a revista íntima consiste em medida vexatória, efetivamente violadora de direitos mínimos da mulher, à própria dignidade e honra.

A falha do legislador em, efetivamente, coibir o ato, não deve ser utilizado por presídios que, justificando pela precariedade do sistema penitenciário ou necessidade de maior segurança para evitar crimes nos presídios, submeter à mulher a já citada medida. Nesse sentido, embora não haja expressamente afirmado o interdito da realização da medida, o Superior Tribunal de Justiça demonstra que é defensor da não realização de revistas íntimas nos presídios. Para tanto, editou o Informativo $\mathrm{n}^{\circ} .659$, evidenciando que a prova será ilícita quando for a revista realizada com base exclusivamente em denúncia anônima (BRASIL, 2021). Ressalte-se, ainda, a ideia de que o relator do caso que originou o tema do informativo, ministro Rogério Schietti Cruz, proferiu voto no sentido de reconhecer o aviltamento mencionado.

Aqui cabe salientar que, mesmo que em seu informativo o texto tenha se restringido ao fato de debater acerca da ilicitude da prova, quando a revista é oriunda de denúncia anônima, a ratio decidendi é a existência do direito da minoria mulher como uma garantia da dignidade humana, em reflexo prático.

Aqui cabe trazer, primeiramente, o esclarecimento quanto ao que se considera situação garantista elencada pelo Superior Tribunal de Justiça. A situação levantada traz à tona a teoria garantista de Luigi Ferrajoli (2010, p. 786), que, dentre os significados possíveis, suscita-se o seguinte:

\footnotetext{
"Garantismo" designa um modelo normativo de direito: precisamente, no que diz respeito ao direito penal, o modelo de "estrita legalidade" SG, próprio do Estado de direito, que sob o plano epistemológico se caracteriza como um sistema cognitivo ou de poder mínimo, sob o plano político se caracteriza como uma técnica de tutela idônea a minimizar a violência e maximizar a liberdade e, sob o plano jurídico, como um sistema de vínculos impostos à função punitiva do Estado em garantia dos direitos dos cidadãos. É consequentemente, "garantista" todo sistema penal que se conforma normativamente com tal modelo e que o satisfaz efetivamente.
}

De efeito, entende-se do termo garantismo a ideia de "garantia", efetivação, proteção, seguridade, defesa, preservação de pessoas ante o arbítrio estatal. Assim, o 
garantismo conforma o reflexo das limitações materiais e formais quanto à atuação estatal, em nome de uma proteção de normas, primados e regras preestabelecidas (AVILA, 2017).

Alguns autores chegam a tratar da existência de um "garantismo feminista", ao percorrer este caminho do Poder Punitivo ante uma criminologia feminista (MARTINS; GAUER, 2020). Conquanto não configure um assunto acabado, é notório que o garantismo, com esta ideia de proteção material a direitos, se coaduna com uma ideação de tutela diferenciada, ativa, e sócio-constituída da mulher como sujeito de direitos perante o ordenamento jurídico. Portanto, ante uma base axiológica, a compreensão do garantismo encaixa-se bem à teoria do feminismo, e, consequentemente, melhor tutela dos direitos da mulher (UNZUETA, 1992).

De tal maneira, as revistas íntimas devem ser interpretadas ante uma necessidade, perante uma visão sócio-histórica e na presença do sistema de garantias fundamentais. Este consiste na construção de uma epistemologia adequada à proteção das pessoas atingidas.

\section{A revista íntima e a CORTEIDH}

Para a compreensão do ordenamento jurídico nacional, deve-se fazer o estudo de modo comparativo, vivo e com a percepção de uma inserção do Brasil no ordenamento jurídico mundial. Assim, muitas vezes, a concepção de direitos sócio-históricos não vem de um direito interno, mas decorre da pressão internacional e da necessidade de adequação das normas nacionais ao restante do mundo. Para tal, o sistema brasileiro abre "as portas" ante a possibilidade do controle de convencionalidade.

O controle de convencionalidade consiste numa doutrina por meio da qual se aplicam as convenções internacionais com a recorrência ao artigo $5^{\circ}$, parágrafos $2^{\circ}$ e $3^{\circ}$ da Constituição da República Federativa do Brasil de 1988 (CRFB/88). Tem-se, em especial, aqui, a Convenção Americana de Direitos Humanos (CADH) ou normas de direitos humanos incluídas no bloco de constitucionalidade, em detrimento das normas de direito interno, de maneira que seja feita uma confrontação do material normativo, tomando por base os dados do caso concreto, e tendo como resultado a elaboração de uma sentença ou acórdão judicial que ratifique a proteção de direitos humanos. 
Daí, o confronto normativo entre o Direito material, substancial, previsto internacionalmente, ante o direito nacional, implica a necessidade de uma novação, ação ou omissão em confronto com a boa técnica jurídica (GUERRA; MOREIRA, 2017). Ademais, quando, perante a $\mathrm{CADH}$, o controle de convencionalidade aufere respaldo a garantir direitos aos nacionais, como dispõe Alcalá (2012, p. 134),

El control de convencionalidad que debe ser desarrollado por los jueces nacionales
implica internalizar en su actividad jurisdiccional que son jueces interamericanos
en el plano nacional, debiendo siempre garantizar los atributos de los derechos
contenidos en la CADH, impidiendo que estos sean afectados por normas jurídicas
de derecho interno o conductas y actos de agentes del Estado que desconozcan los
estándares mínimos determinados convencionalmente.

Nesta esteira, o controle de convencionalidade no Brasil acontece difusa ou concentradamente, implicando a apreciação do Poder Judiciário desta aplicação de normas internacionais e, nessa evolução, na consecução de direitos (MENDES, 2009). Ademais, incumbe ao Supremo Tribunal Federal, não apenas, a análise de proteção aos direitos fundamentais, como também aos direitos humanos, e, portanto, uma análise material de defesa de direitos.

Relativamente à proteção da CADH, Mazzuoli (2018) indica os reflexos dessa Corte no ordenamento nacional, implicando a reinterpretação do Direito nacional e, sobretudo, a formação de conceitos próprios de convivência entre as normas nacionais e as regras externas.

Assim, trazendo o tema ora analisado, pertinente à constitucionalidade ou não da realização de revista íntima, o fato não deveria demandar dúvida por parte dos tribunais ou dos juízes, especificamente pelo exposto do controle de convencionalidade.

Cumpre ser destacado, ainda, o argumento de que a situação objeto de análise transporta a necessidade de evidenciar os casos dos diálogos verticais e diálogos horizontais de normas. Na disciplina de Mazzuoli (2010, p.165), o diálogo vertical caracteriza-se como aquelas conversas mais diretas, mais agressivas, entre as fontes internacionais, produzindo antinomias, ensejando os conceitos de inserção e transigência. Por inserção, tem-se o uso da norma internacional no País, transigência, tem-se a redução do alcance de uma norma nacional para dar espaço às de cariz internacional. 
Em suma, consiste no fato de o direito internacional dos direitos humanos e o direito interno brasileiro possuírem uma relação de complementaridade ou de integração. Fica evidente pelas normas, tanto da CRFB/88 citadas, como as da Convenção Americana de Direitos Humanos. Portanto, aplica-se a um determinado caso concreto, com o único escopo de se obter um interesse mais favorável à pessoa humana e, na situação objeto deste ensaio, a não realização da revista íntima. Para melhor elucidar a temática, Mazzuoli aduz (2010, p. 154 e 155):

Os diálogos horizontais podem se dar de duas maneiras: a) quando a norma de direito constitucional é mera repetição de um direito que já vem expresso em tratado internacional, caso em que, inegavelmente, o valor extrínseco da norma convencional será o de norma materialmente constitucional, possuindo o poder de revogar todas as disposições internas em contrário; ou b) quando a norma internacional vem a suprir lacunas existentes tanto na Constituição como em leis infraconstitucionais. O primeiro caso denomina-se diálogo de complementaridade e o segundo, diálogo de integração.

Assim, conquanto o fato de a $\mathrm{CRFB} / 88$, tanto quanto a Convenção, não terem expressamente suscitado o caso das revistas, a Comissão Interamericana de Direitos Humanos (CIDH) e a CORTEIDH já analisaram ocorrência análoga, em que se discutiu a legalidade da realização de revistas íntimas, de modo que consolidou o entendimento de que há efetiva violação de direitos em sua execução.

O caso chegou à CIDH e foi abordado no Relatório n ${ }^{\circ} .38 / 96$, de 15 de outubro de $1996,{ }^{8}$ consistindo em situação na qual as autoridades penitenciárias da Unidade 1 do SPF da

\footnotetext{
8 “87. O procedimento não é ilegal per se. Contudo, quando o Estado procede a qualquer tipo de intervenção física numa pessoa, deve observar certas condições para garantir que não ocorra angústia e humilhação maior do que a inevitável. Para aplicar essa medida, sempre deverá existir um mandado judicial que assegure certo grau de controle sobre a decisão referente à necessidade da sua aplicação e para que a pessoa que seja submetida à mesma não se sinta indefesa em face das autoridades. Por outro lado, o procedimento sempre deve ser realizado por pessoal idôneo, que utilize o devido cuidado para não produzir lesões físicas, e o exame deve ser efetuado de tal maneira que a pessoa ao mesmo submetida não sinta que a sua integridade mental e moral esteja sendo afetada. 88. No que se refere ao artigo 5.3, a Comissão não dispõe de evidência indicativa de que a revista vaginal foi efetuada com a intenção de estender o castigo do marido da Senhora X à sua família. Além disso, não compete à Comissão presumir razões que não tenham sigo objetivamente verificadas. (P. 11) 89. Em conclusão, a Comissão opina que as autoridades do Estado argentino, ao realizarem revistas vaginais sistemáticas de $\mathrm{X}$ e Y, violaram seus direitos à integridade física e moral, incorrendo assim em transgressão do artigo 5 da Convenção. 93. Contudo, a Comissão deseja salientar que este caso representa um aspecto íntimo especial da vida privada de uma mulher e que o procedimento em questão, seja a sua aplicação justificável ou não, pode provocar angústia e vergonha profunda em quase todas as pessoas ao mesmo submetidas. Ademais, a aplicação do procedimento a uma menina de 13 anos pode resultar em grave dano psicológico, difícil de avaliar. A Senhora X e sua filha tinham direito ao respeito de sua intimidade, dignidade e honra ao procurarem exercer o direito à família, apesar de um dos seus membros estar detido. Tais direitos só deveriam ter sido limitados no caso de uma situação muito grave e em circunstâncias muito específicas e, nesse caso, com o estrito cumprimento, pelas autoridades, das
} 


\section{A REVISTA ÍNTIMA EM MULHERES COMO CONDIÇÃO PARA O INGRESSO EM UNIDADES PRISIONAIS: ANÁLISE À LUZ DA JURISPRUDÊNCIA DA CORTE INTERAMERICANA DE DIREITOS}

HUMANOS

Argentina adotaram a prática de efetuar revistas vaginais em todas as mulheres que desejassem ter contato pessoal com os presos. Assim, uma senhora, acompanhada de sua filha, esta com apenas 13 anos, que tentavam visitar seu parente que estava recolhido ao cárcere, teve que se submeter à revista íntima.

Em palavras claras e bem elaboradas, restou evidenciado o fato de que a medida da revista íntima, além de vexatória, é hábil a violar diversos direitos inerentes à pessoa da mulher, inclusive com sua conclusão elaborada. ${ }^{9}$

Outro caso semelhante, seja este o precedente Miguel Castro vs. Peru, no ano de 2006, a CORTEIDH (2006) seguiu o mesmo posicionamento, repugnando a revista íntima, por ser uma violência sexual institucionalizada.

Verifica-se que, apesar de não ser regulamentada pelo Direito brasileiro (em legislação de abrangência nacional) a interdição à revista íntima, o posicionamento pugnado pela CORTEIDH é no sentido de que o procedimento é vexatório, repugnante e efetivo violador de direitos da mulher, como dignidade e integridade física, podendo em algumas

regras anteriormente definidas para garantir a legalidade da prática. (P. 12) 94. A Comissão conclui que, ao efetuarem as autoridades revistas vaginais da Senhora $\mathrm{X}$ e de sua filha sempre que desejam manter contato pessoal com o marido da Senhora X, violaram seu direito à proteção da honra e dignidade, consagrado no artigo 11 da Convenção. 99. As visitas com contato pessoal não são um direito e, em muitos países, nem sequer constituem uma opção. Em geral, a possibilidade de visitas de contato pessoal é deixada à discrição das autoridades penitenciárias. Porém, quando o Estado regulamenta o modo pelo qual os reclusos e suas famílias exercem o direito à família, não pode impor condições ou aplicar procedimentos que constituam transgressão de qualquer um dos direitos consagrados na Convenção, pelo menos sem o devido processo. Todos os Estados Partes da Convenção têm obrigação de certificar-se de que a ação do Estado e a organização da sua estrutura interna e do seu sistema jurídico se situem dentro de certos limites de legalidade. (p. 12/13) 100. Portanto, a Comissão conclui que, ao requererem as autoridades do Estado argentino que a Senhora X e sua filha se submetessem a revistas vaginais sempre que desejavam manter contato pessoal com o marido da Senhora X, exerceram interferência indevida no direito à família dos peticionários" (CIDH, 2021).

9 “115. O artigo 163 do projeto de lei, que se refere à substituição da revista manual por sensores não invasivos ou outras técnicas não tácteis apropriadas e eficazes é, em princípio, compatível com as recomendações da Comissão. Não obstante, o citado artigo deixa de mencionar expressamente o tipo de inspeção corporal invasiva que foi analisada no presente relatório. A Comissão reitera que as revistas vaginais ou outras inspeções corporais de tipo invasivo devem ser realizadas por pessoal médico credenciado". (P. 15). 116. Portanto, a Comissão conclui que, ao impor uma condição ilegal para a realização das visitas à penitenciária sem dispor de mandado judicial ou oferecer as garantias médicas apropriadas, e ao efetuar revistas e inspeções nessas condições, o Estado argentino violou os direitos da Senhora X e sua filha Y consagrados nos artigos 5, 11 e 17 da Convenção, em correlação com o artigo 1.1, que dispõe pela obrigação do Estado argentino de respeitar e garantir o pleno e livre exercício de todas as disposições reconhecidas na Convenção. No caso da menor Y, a Comissão conclui que o Estado argentino também transgrediu o artigo 19 da Convenção" (CIDH, 2021). 
circunstâncias, inclusive, configurar abuso sexual. Em momentos como o atual, quando, constantemente, se deparam os esforços realizados pelas mulheres em demanda pelo respeito aos seus direitos, em busca da igualdade na sociedade, manter medidas como a da revista íntima, sujeitando-a à circunstância de análise de suas reentrâncias físicas por uma pessoa completamente estranha, não deve prosperar.

\section{A revista íntima na visão do STF e STJ}

Do ponto de vista estritamente normativo, não se percebeu nenhum instrumento legal que garanta a possibilidade do uso do mecanismo denominado visita íntima. Após, no entanto, o tema ter sido analisado por tribunais de justiça e pelo Superior Tribunal de Justiça, finalmente chegou ao Supremo Tribunal Federal, situação que demanda sua apreciação, já tendo sido visto, inclusive, que o caso analisado pelos ministros é detentor de repercussão geral.

O caso fático analisado pelo Supremo Tribunal Federal ocorreu no Estado do Rio Grande do Sul, quando uma mulher tentou adentrar o presídio de segurança máxima contendo no interior de sua vagina cerca de 100 gramas de substância entorpecente. Como, no presídio, eram realizadas, genericamente, as revistas íntimas, a mulher foi presa em flagrante com a substância.

Analisado o caso pela $1^{\text {a }}$ Vara Criminal do Foro Regional do Partenon, Porto Alegre/RS, entendeu o magistrado que o fato configurou ilícito penal, de modo que condenou a ré pela prática do crime tipificado no Art. 33, caput, com incidência de seu parágrafo $4^{\circ}$, e do Art. 40, inciso III, todos da Lei $\mathrm{n}^{\mathrm{o}} .11 .343 / 06^{10}$, fixando a pena em um ano, 11 meses e dez dias de reclusão.

\footnotetext{
10 “Art. 33. Importar, exportar, remeter, preparar, produzir, fabricar, adquirir, vender, expor à venda, oferecer, ter em depósito, transportar, trazer consigo, guardar, prescrever, ministrar, entregar a consumo ou fornecer drogas, ainda que gratuitamente, sem autorização ou em desacordo com determinação legal ou regulamentar: Pena reclusão de 5 (cinco) a 15 (quinze) anos e pagamento de 500 (quinhentos) a 1.500 (mil e quinhentos) dias-multa. $[\ldots] \S 4^{\circ}$ Nos delitos definidos no caput e no $\S 1^{\circ}$ deste artigo, as penas poderão ser reduzidas de um sexto a dois terços, vedada a conversão em penas restritivas de direitos, desde que o agente seja primário, de bons antecedentes, não se dedique às atividades criminosas nem integre organização criminosa. Art. 40. As penas previstas nos arts. 33 a 37 desta Lei são aumentadas de um sexto a dois terços, se: [...] III - a infração tiver sido cometida nas dependências ou imediações de estabelecimentos prisionais, de ensino ou hospitalares, de sedes de entidades estudantis, sociais, culturais, recreativas, esportivas, ou beneficentes, de locais de trabalho coletivo, de recintos onde se realizem espetáculos ou diversões de qualquer natureza, de serviços de tratamento de
} 


\section{A REVISTA ÍNTIMA EM MULHERES COMO CONDIÇÃO PARA O INGRESSO EM UNIDADES PRISIONAIS: ANÁLISE À LUZ DA JURISPRUDÊNCIA DA CORTE INTERAMERICANA DE DIREITOS \\ HUMANOS}

Irresignada com a situação, a defesa apelou ao Tribunal de Justiça do Estado do Rio Grande do Sul, que proferiu acórdão no sentido de absolver a ré, suscitando, em suma, que se trata de crime impossível e de mera conduta, utilizando como fundamento legal para a absolvição o Art. 386, II e III, do Código de Processo Penal Brasileiro, ${ }^{11}$ seguindo a natural fase recursal de apreciação do Poder Judiciário.

Este caso foi analisado pelo Superior Tribunal de Justiça, que se limitou às questões da licitude ou ilicitude de provas, sem adentrar discussões mais profundas acerca do procedimento. Aqui cabe salientar que, bem antes deste julgado, já havia críticas fortes a este procedimento, que reforça um Estado de dominação e hipercriminalização feminina (PAULA; SANTANA, 2012).

Assim a análise feita pelo Superior Tribunal de Justiça não adentrou o caso da completa violação de direitos como dignidade e intimidade que a realização de revista íntima enseja. Pelo contrário, apenas agravou a situação deveras indecisa acerca do atual cenário do procedimento, se ele é legal ou não, em reflexo a um machismo estrutural, que, diante de um contexto de evidente ofensa a direitos fundamentais, restringe-se a questões formais, dando aparência de legalidade a sucumbir às garantias impostas a grupos vulneráveis (BRASIL, 2021b).

Percebe-se isso, ainda, quando verificada que a Corte mudou seu posicionamento com relação ao caso apreciado no ano de 2016, ao editar o Informativo de Jurisprudência $n^{\circ}$ 659, já anteriormente abordado, no qual pugna ser a revista íntima uma conduta atentatória à dignidade da pessoa humana, o que enaltece a tendência de vedar a revista.

Nesse sentido, apercebe-se a dicotomia entre a posição pública, mediante normativos genéricos e orientações, e a posição individual. Enquanto, em público, se fala, em expansão de direitos, garantias e proteção à dignidade humana, nas situações particulares tem-se o uso indiscriminado das formalidades como contragarantias. Isto é, o formalismo excessivo rompe

dependentes de drogas ou de reinserção social, de unidades militares ou policiais ou em transportes públicos" (BRASIL, 2020c).

11 "Art. 386. O juiz absolverá o réu, mencionando a causa na parte dispositiva, desde que reconheça:

I - estar provada a inexistência do fato; II - não haver prova da existência do fato; III - não constituir o fato infração penal" (BRASIL, 2020d). 
as bases da formalidade valorativa, as quais implicam, efetivamente, a atividade de julgar e enfrentar temas sensíveis, como a ofensa a direitos de minorias (OLIVEIRA, 2006).

O Supremo Tribunal Federal analisou, por sua vez, o caso por meio do Recurso Extraordinário nº 959.620. Assim, em voto proferido por Edson Fachin, entendeu-se que só seria possível a revista íntima antes do ingresso em estabelecimentos prisionais de forma excepcional, motivada, com o consentimento da visitante, por pessoas do mesmo gênero e mediante protocolos preestabelecidos.

Conforme análise do voto, este amplamente correto e respeitoso aos direitos da mulher, a busca pela análise do caso é ratificar que a revista íntima se mostra uma conduta não só vexatória e violadora de direitos, como à dignidade da pessoa humana, honra e integridade física, mas também por ser inconstitucional, já que viola garantias mínimas dispostas na CRFB/88.

Deve ser destacado o fato de que o ministro Luís Roberto Barroso e a ministra Rosa Weber seguiram o entendimento firmado por Edson Fachin, tendo como divergência, até então, a do ministro Alexandre de Moraes, pois acredita que a revista íntima deve ser aplicada, sim, aos presídios, mas desde que em observância a algumas regras mínimas. Aqui, deve-se dizer que não há previsão de quais sejam estas regras mínimas, ou mesmo como seria possível fazer a vistoria das partes íntimas de uma pessoa sem violar a sua dignidade.

Fato que merece ser destacado com relação à análise do caso é que o grande interessado na manutenção da prática, o Departamento Penitenciário Nacional, se restringiu a afirmar que a revista íntima é necessária para a preservação da segurança prisional, colacionando dados que evidenciam o grande número de apreensões feitas em decorrência da revista, bem como enalteceu o fato de que objetos, como bilhetes, ou dados inscritos na pele da pessoa, não são passíveis de verificação pelos aparelhos eletrônicos. ${ }^{12}$

Aduziram, também, o fato de que excluir a revista íntima ensejará grave prejuízo ao Sistema Penitenciário Federal, em especial, para as penitenciárias de segurança máxima, onde o escopo é evitar que as pessoas ali presas tenham qualquer tipo de contato com o meio exterior, como, por exemplo, utilizando-se de bilhetes. Tais alegações, entretanto, não devem

\footnotetext{
${ }^{12}$ Disponível em: https://url.gratis/5eAQY.
} 
prosperar, pelo que se menciona, por azado o momento, o Art. $1^{\text {a }}$, III, e Art. $5^{\circ}$, incisos III e X, ambos da CRFB/88. ${ }^{13}$

Este julgamento não foi encerrado ainda até a data da edição deste texto, vez que está, sob vistas, com o ministro Dias Toffoli. Se, todavia, se acompanhar a lógica de proteção a direitos, espera-se um resultado pela concessão da ordem.

Por outro lado, ante a existência de questões institucionalizadas, não é possível afirmar categoricamente que a proteção e tutela a estes direitos vai ocorrer. Racional é se exprimir que esta deve ser analisada ante as proteções fundamentais e, sobretudo, perante o controle de convencionalidade.

\section{Considerações finais}

Tem-se a proteção dos direitos dos grupos em situação de vulnerabilidade como garantias que precisam integrar o ordenamento jurídico, ante a necessidade de uma reinterpretação do Direito, com arrimo em conceitos epistemológicos próprios. Assim, os direitos das mulheres precisam ser entendidos em relação ao machismo estrutural e diante de uma percepção própria que a mera legalidade ou o mero formalismo é incapaz de suprir.

Assim, o tema das revistas íntimas, ou seja, daquele modelo de verificação e controle dos presos que passam pela situação vexatória de retirada de roupas, e protocolos de humilhação institucional, é combatido internacionalmente. A CORTEIDH já se posicionou sobre a realização de revistas íntimas, de modo que pugnou pela sua ilegalidade.

Segundo a Corte, os direitos violados pelo procedimento são expressamente previstos na Convenção Americana de Direitos Humanos, sendo estes o direito à integridade física e psíquica, honra, dignidade da pessoa humana e proteção à família, ressaltando que esses direitos também se encontram previstos na CRFB/88.

\footnotetext{
13 “Art. $1^{\circ}$ A República Federativa do Brasil, formada pela união indissolúvel dos Estados e Municípios e do Distrito Federal, constitui-se em Estado Democrático de Direito e tem como fundamentos: [...] III - a dignidade da pessoa humana; Art. $5^{\circ}$ Todos são iguais perante a lei, sem distinção de qualquer natureza, garantindo-se aos brasileiros e aos estrangeiros residentes no País a inviolabilidade do direito à vida, à liberdade, à igualdade, à segurança e à propriedade, nos termos seguintes: [...] III - ninguém será submetido a tortura nem a tratamento desumano ou degradante; [...] X - são invioláveis a intimidade, a vida privada, a honra e a imagem das pessoas, assegurado o direito a indenização pelo dano material ou moral decorrente de sua violação" (BRASIL, 2020e).
} 
Aqui se tem o falso dilema entre "proteger a sociedade" e "proteger a honra", quando, na atualidade, já existem medidas alternativas tão eficazes quanto a revista íntima, como é o caso dos escâneres corporais. Alegar que a segurança pública deve ser priorizada em face da dignidade da pessoa humana, esta violada quando da realização da revista, não é hábil na sociedade atual, especialmente pelos constantes movimentos das mulheres por busca de direitos - isso porque tem-se o direito como instrumento contramajoritário.

Neste comenos, observa-se que o tema chegou ao Supremo Tribunal Federal, que vem caminhando numa linha que deva aportar na ilegalidade da revista íntima.

Ademais, o problema já deveria ter sido superado, há tempos, pelo Direito brasileiro. A doutrina do controle de convencionalidade foi devidamente implementada no sistema patrial, sob o enfoque de emprego das decisões da Convenção Americana de Direitos ou das normas de direitos humanos incluídas em tratados internacionais ao bloco de constitucionalidade, sobre as normas de Direito interno.

Deste modo, é necessário que o Direito brasileiro esteja em consonância com os entendimentos da CORTEIDH, devendo prevalecer o posicionamento pela ilegalidade de realização da medida da revista íntima e, consequentemente, o resultado em cadeia da prática desse ato, como a ilegalidade de provas obtidas pela revista.

\section{REFERÊNCIAS}

ALCALÁ, Humberto Nogueira. Diálogo interjurisdiccional, control de convencionalidad y jurisprudencia del tribunal constitucional en periodo 2006 - 2011. Revista do Curso de Direito, São Luís, v. 2, n. 4, p. 131-203, dez. 2012. Semestral.

AVILA, Jheison Torres. La teoría del Garantismo: poder y constitución en el Estado contemporáneo. Rev. Derecho, Barranquilla, n. 47, p. 138-166, June 2017 . Disponível em: http://www.scielo.org.co/scielo.php?script=sci_arttext\&pid=S012186972017000100138\&lng=en\&nrm=iso. Acesso em: 10 Dez. 2017.

AYALA REBOLLEDO, Stephanie Gisselle. Revista íntima em presídios: violação ao direito da dignidade humana das mulheres? Cooperação Internacional STF. 2019. Disponível em: https://url.gratis/a7CLc. Acesso em: 05 abr. 2021.

BRASIL. Constituição da República Federativa do Brasil de 1988. Brasília, 05 out. 1988. Disponível em: http://www.planalto.gov.br/ccivil_03/constituicao/constituicao.htm. Acesso em: 23 nov. $2020 \mathrm{e}$. 


\section{A REVISTA ÍNTIMA EM MULHERES COMO CONDIÇÃO PARA O INGRESSO EM UNIDADES PRISIONAIS: ANÁLISE À LUZ DA JURISPRUDÊNCIA DA CORTE INTERAMERICANA DE DIREITOS \\ HUMANOS}

BRASIL. Decreto-Lei no 3.689, de 1941. Código de Processo Penal. Rio de Janeiro, 03 out. 1941. Disponível em: https://url.gratis/FY3Uv. Acesso em: 23 nov. 2020d.

BRASIL. Lei $\mathbf{n}^{\mathbf{0}}$ 13.271, de 2016. Dispõe sobre a proibição de revista íntima de funcionárias nos locais de trabalho e trata da revista íntima em ambientes prisionais. Brasília, 15 abr. 2016. Disponível em: https://url.gratis/GLEi6. Acesso em: 23 nov. 2020 b.

BRASIL. Lei n⿳0 11.343, de 2006. Institui o Sistema Nacional de Políticas Públicas sobre Drogas. Brasília, 23 ago. 2006. Disponível em: https://url.gratis/7ET0q. Acesso em: 23 nov. 2020c.

BRASIL. Superior Tribunal de Justiça. Informativo n 659. Brasília, 22 nov. 2019.

Disponível em: https://url.gratis/C2VyP. Acesso em: 23 jan. 2021a.

BRASIL. Superior Tribunal de Justiça. Recurso Especial no 1.458.024 - RS (2014/01316618). Brasília, 01 fev. 2016. Disponível em: https://url.gratis/SqP6n. Aceso em: 23 jan. 2021b.

BRASIL. Supremo Tribunal Federal. Recurso Extraordinário no. 959620-RS. Brasília, Disponível em: https://url.gratis/dI9Kw. Acesso em: 23 nov. 2020a.

BREGA FILHO, Vladimir; ALVES, Fernando de Brito. O direito das mulheres: uma abordagem crítica. Argumenta Journal Law, v. 10, n. 10, p. 131-142, 2009.

CAPOTORTI, Francesco. Study on the rights of persons belonging to ethnic, religious and linguistic minorities. New York: United Nations, 1979.

CIDH. Caso X e Y (menor) v. Governo da Argentina. 1996. Disponível em: http://cidh.oas.org/annualrep/96port/Caso11506.htm. Acesso em: 14 Abr. 2021.

CORTEIDH. Caso Miguel Castro Castro vs. Perú. 2006. Disponível em: http://www.corteidh.or.cr/docs/casos/articulos/seriec_160_esp.pdf. Acesso em: 14 Abr. 2021.

CORTEIDH. Convenção Americana de Direitos Humanos de 1969. Disponível em:

https://www.cidh.oas.org/basicos/portugues/c.convencao_americana.htm. Acesos em: 23 nov. 2020.

ESTADO DO CEARÁ. Portaria no. 1.217/2014. Ceará. 09 de dezembro de 2014. Disponível em: http://corregedoria.tjce.jus.br/wp-content/uploads/2015/01/18-2015.pdf. Acesso em: 23 nov. 2020.

FERRAJOLI, Luigi. Direito e Razão: teoria do garantismo penal. 3. ed. rev. São Paulo: Revista dos Tribunais, 2010.

GOELLNER, Silvana Vilodre. Feminismos, mulheres e esportes: questões epistemológicas sobre o fazer historiográfico. Movimento. Vol. 13, n. 2 (maio/ago. 2007), p. 171-196, 2007.

GUERRA, Sidney; MOREIRA, Thiago Oliveira. Contornos atuais do controle de convencionalidade doméstico. In: GONÇALVES, Rubén Miranda; VEIGA, Fábio da Silva (org.). Los Desafios Jurídicos a La Gobernança Global: uma perspectiva para los próximos siglos. Brasília: Advocacia-Geral da União, 2017. Cap. 5. p. 67-76. 
MACHADO, Bruno Amaral; SLONIAK, Marcos Aurélio. Disciplina ou ressocialização? Racionalidades punitivas, trabalho prisional e política penitenciária. Rev. Direito GV , São Paulo, v. 11, n. 1, p. 189-222, junho, 2015. Disponível em: http://www.scielo.br/scielo.php?script=sci_arttext\&pid=S180824322015000100189\&lng=en\&nrm=iso. Acesso em: 05 Abr. 2021.

MARTINS, Argemiro Cardoso Moreira; MIZUTANI, Larissa. Direito das Minorias Interpretado: o compromisso democrático do Direito brasileiro. Sequência: Estudos Jurídicos e Políticos, v. 32, n. 63, p. 319-352, 2011.

MARTINS, Fernanda; GAUER, Ruth M. C.. Poder Punitivo e Feminismo: percursos da criminologia feminista no Brasil. Rev. Direito Práxis, Rio de Janeiro , v. 11, n. 1, p. 145178, Mar. 2020. Disponível em: http://www.scielo.br/scielo.php?script=sci_arttext\&pid=S217989662020000100145\&lng=en\&nrm=iso. Acesso em: 14 abr. 2021.

MAZZUOLI, Valério de Oliveira. Tratados internacionais de direitos humanos e direito interno. São Paulo: Saraiva, 2010.

MAZZUOLI, Valério de Oliveira. Controle Jurisdicional da Convencionalidade das Leis. 5. ed. Rio de Janeiro: Forense, 2018.

MENDES, Gilmar. Novos Aspectos do Controle de Constitucionalidade Brasileiro. Revista de Direito Público, Brasília, v. 6, n. 27, p. 7-45, jun. 2009. Bimestral.

OLIVEIRA, Carlos Alberto Álvaro de. O formalismo-valorativo no confronto com o formalismo excessivo. Revista da Faculdade de Direito da UFRGS, v. 26, n. 26, 2006.

SANTOS, Boaventura de Sousa; MENESES, Maria Paula; NUNES, João Arriscado. "Introdução: para ampliar o cânone da ciência: a diversidade epistemológica do mundo", in B. S. Santos (org.), Semear outras soluções. Porto: Afrontamento, 2004, p. 23101.

TRIBUNAL DE JUSTIÇA DO ESTADO DO RIO GRANDE DO SUL - TJ/RS. Apelação no. 70053559068. Relator: Des. Nereu José Giacomolli. DJe: 05/06/2013. Disponível em: https://www.tjrs.jus.br/servicos/diario_justica/dj_principal.php?tp=5\&ed=5092\&pag=107. Acesso em: 23 nov. 2020.

UNZUETA, María Angeles Barrere. Feminismo y garantismo: ¿Una teoría del derecho feminista?. Anuario de Filosofía del Derecho, n. 9, p. 75-90, 1992. 